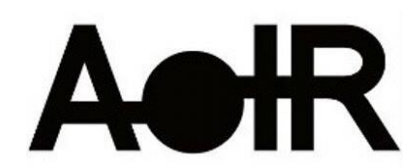

Selected Papers of \#AoIR2021:

The 22nd Annual Conference of the

Association of Internet Researchers

Virtual Event / 13-16 Oct 2021

\title{
THE CONVERSATION, TEN YEARS ON: ASSESSING THE IMPACT OF A UNIQUE SCHOLARLY PUBLISHING INITIATIVE
}

\author{
Michelle Riedlinger \\ Digital Media Research Centre, Queensland University of Technology
}

Alice Fleerackers

Scholarly Communications Lab, Simon Fraser University

Axel Bruns

Digital Media Research Centre, Queensland University of Technology

Jean Burgess

Digital Media Research Centre, Queensland University of Technology

Lars Guenther

Department of Social Sciences, University of Hamburg

Marina Joubert

CREST, Stellenbosch University

Kim Osman

Digital Media Research Centre, Queensland University of Technology

\section{Panel Introduction}

The Conversation (theconversation.com) represents a unique model for communicating scholarly research to the general public via explanatory journalism. Rather than relying on scholars' personal networks, the promotional efforts of university press offices, or requests from science journalists for comments on current developments, The Conversation offers a platform for scholars across all disciplines to pitch their own stories, gain support from its in-house journalistic staff to develop those stories for a general audience, and see the resulting articles published under Creative Commons licences, enabling them to be republished by commercial and public service news outlets around the world. The overall success of this model, which may be described as

Suggested Citation (APA): Riedlinger, M., A. Fleerackers, A. Bruns, J. Burgess, L. Guenther, M. Joubert, and K. Osman. (2021, October). The Conversation, Ten Years On: Assessing the Impact of a Unique Scholarly Publishing Initiative. Panel presented at AolR 2021: The 22nd Annual Conference of the Association of Internet Researchers. Virtual Event: AolR. Retrieved from http://spir.aoir.org. 
'journalism-as-a-service', is evident: articles from The Conversation are regularly republished by major international news outlets from the New York Times through CNN to The Guardian, as well as by domestic outlets across the eight countries and regions in which The Conversation now operates.

The tenth anniversary of the publication's launch in Melbourne, Australia, in March 2011 provides a suitable opportunity to assess the extent to which The Conversation has achieved its stated aims, and to examine the challenges it continues to face. In addition to the Australian edition, The Conversation now publishes to audiences in the UK, US, France, Spain, Africa, Indonesia, Anglophone as well as Francophone Canada, and New Zealand, and produces a generic 'Global Perspectives' edition that draws content from all regional and national versions; it employs more than 100 editors across its global network, and it attracted nearly 750 million article visits in 2020 alone (Ketchell, 2021). Yet the different academic, social, media, and political environments within which these editions operate, as well as their diverging organisational structures and publishing track records, mean that considerable variations between these editions remain; for instance, the longest-running and best-established national edition the Australian Conversation must now carefully prioritise which story pitches from scholars it can accommodate, whereas other more recently launched offshoots are still working to attract submissions from local scholars, and to gain the trust of domestic audiences, academic institutions, and media partners. Similarly, the different national academic systems that The Conversation engages with emphasise the publication of scholarly work to varying degrees, and domestic media audiences may similarly seek out evidence-based scholarly perspectives to differing extents.

Drawing on contributions from scholars across a wide range of academic systems and traditions, this panel assesses the success and impact of The Conversation in its tenth year from a number of angles. First, the continuing COVID-19 pandemic has further highlighted the need for accessible, clearly communicated scientific knowledge about the virus, as well as medical and public health responses to it; at the same time, earlystage research is emerging rapidly against a broad context of uncertainty. In the first paper in this panel, we investigate the relative amplification across social media platforms of articles in The Conversation containing links to research preprints related to COVID-19, exploring how social media users are engaging with and negotiating the (un)certain nature of this early-stage research.

Second, we continue our focus on the social media impact of The Conversation by assessing the circulation of its content on public Facebook pages in Australia and Anglophone Canada. This compares the oldest national edition of The Conversation with its youngest, and pays particular attention to whether, in each domestic context, the publication has achieved its aim to translate scholarly insights to a broad general audience, or whether its content circulates unevenly amongst the Facebook userbase. We assess this particularly by examining the sharing of Conversation articles alongside other domestic news content, which provides a proxy for the sharing pages interests and ideologies.

Third, we examine the extent to which The Conversation's African edition is able to serve as an agenda-setter for both mainstream and social media debates in the region. 
Drawing on internal data from The Conversation on content republication in journalistic outlets and content sharing on Facebook and Twitter, we investigate how these different media have engaged with content published in TC Africa, and find considerable differences in the topical areas they emphasise: journalistic media drew predominantly on political and economic coverage in The Conversation, while social media users tended to amplify its coverage of social and societal issues.

Fourth, we combine internal Conversation data, Facebook engagement, and the outcomes of a series of interviews with scholars from Australia and Canada who have published in The Conversation to review the experience of publishing scholarly insights for a general audience, and examine whether there are particular patterns in the themes, topics, and disciplines that attract the greatest amount of engagement. This provides new insights into the success of The Conversation in amplifying scientific expertise and supporting the public communication goals of scholars and their institutions.

Taken together, the panel provides a broad-ranging and multi-faceted assessment of the status of the Conversation project, in its tenth year of operation. The current COVID19 crisis has particularly highlighted the crisis of expertise and unevenness of scientific literacy amongst journalists, politicians, and the general public. The panel's assessment of the successes and failures of one of the leading digital science communication initiatives of the past decade provides an important reality check, and offers new insights on what can be done to increase the visibility and impact of rigorous scholarly perspectives from all disciplines of research in public and political debates.

\section{References}

Ketchell, Misha. 2021, 25 March. The Conversation Story: Celebrating 10 Years of News from Experts. The Conversation. https://theconversation.com/the-conversationstory-celebrating-10-years-of-news-from-experts-157593 


\title{
Paper 1
}

\section{SHARING UNCERTAIN SCIENCE: MAPPING THE CIRCULATION OF COVID-19 PREPRINT RESEARCH REPORTED IN THE CONVERSATION ON FACEBOOK AND TWITTER}

\author{
Michelle Riedlinger \\ Digital Media Research Centre, Queensland University of Technology \\ Alice Fleerackers \\ Scholarly Communications Lab, Simon Fraser University \\ Axel Bruns \\ Digital Media Research Centre, Queensland University of Technology \\ Jean Burgess \\ Digital Media Research Centre, Queensland University of Technology
}

During the first few months of the COVID-19 pandemic, The Conversation was one of the 15 media outlets most frequently reporting on COVID-19 research via preprintspublicly available research papers that have yet to be peer reviewed (Fleerackers et al., 2021). While media coverage of preprints has the potential provide urgently-needed, evidence-based guidance on how to prevent the spread of the virus, it can also mislead if the preliminary or unverified nature of the research is not made explicit or potentially flawed findings are interpreted as established facts (Majumder \& Mandl, 2020). The Conversation published 42 stories linking to one or more of the 100 most-cited preprints posted on medRxiv and bioRxiv (two of the most widely used preprint servers) from 1 January to 30 April 2020. After conducting content analyses of these 42 stories, researchers found that fewer than half of the stories included linguistic strategies describing the preprint research as scientifically uncertain (Fleerackers et al., 2021). These linguistic strategies included labelling the work as preprint research, or qualifying the findings as preliminary, not peer reviewed or needing verification.

Understanding The Conversation's preprint coverage is important, both because of the outlet's focus on providing evidence-based content that audiences can use, and its potentially expansive reach as an "amplifier platform" (Osman \& Cunningham, 2020). Given that social media is among the top sources of online news in many countries (Newman et al., 2020), this paper explores its role in content amplification, focusing on how Facebook and Twitter users engaged with The Conversation articles that mentioned COVID-19 preprint research.

\section{Communicating Scientific Uncertainty on Social Media}

On social media, audience perceptions of quality news and the value of content are shaped by a combination of internal editorial decisions and user decisions. Social media channels help media outlets gain large audiences (Deuze, 2008) and engage a broader 
range of audience groups (Deuze et al., 2007). Social media platforms pose new challenges and opportunities for scholars concerned with how scientific uncertainty is understood and communicated outside of scientific forums. It has been recognised for decades that framing research as scientifically uncertain in media reporting does not occur unless the implications for the audience require it. Journalists may ignore uncertainties (Peters \& Dunwoody, 2016) or exaggerate scientific uncertainties when reporting on controversial research areas to appear "balanced" (Corbett \& Durfee, 2004; Dixon \& Clarke, 2013; Zehr, 1999). Readers of media articles manage scientific (un)certainty through a number of strategies (Klawitter \& Hargittai, 2018; Maggio et al., 2020; Metzger et al., 2010): they rely heavily on heuristics when evaluating media content, for example, endorsing articles because they are published by trusted or familiar sources; because they present findings that are consistent with the views of trusted others or which can be triangulated with other data; because they offer perspectives that align with readers' existing beliefs or personal experience; because they present information in a way that readers perceive as balanced and straightforward (i.e. unbiased) (Metzger et al., 2010); or because they include credibility markers, such as numbers, statistics or hyperlinks to scientific research articles (Maggio et al., 2020). However, researchers have yet to determine how scientific uncertainty in media reporting is evaluated and communicated on social media.

\section{How Is Preprint Research Used in The Conversation Articles and How Is Scientific (Un)certainty Represented?}

We investigated The Conversation articles that include preprint research claims purposively, i.e. to support an argument or point of view, to criticise preprints or preprint research, to demonstrate complexity or controversy in the research area, or to highlight gaps in research yet to be filled. We found that the authors of The Conversation articles were more likely to state that the research they reported on was preprint research, or use other linguistic markers of scientific uncertainty, when they disagreed with the findings from preprint research or criticised preprints in general. Authors were less likely to include linguistic markers of uncertainty when using the evidence from preprint research to support their claims, to present the research area as complex or to emphasise gaps in a research area.

\section{Where Are The Conversation Stories Circulating on Facebook and Twitter and How Is Scientific Uncertainty Evaluated and Communicated?}

Using the Facebook public insights tool, Crowdtangle, we collected Facebook posts that shared links to the stories from The Conversation on public groups, pages and verified profiles. We collected Tweets using Twint, a Python-based Twitter scraping tool (Zacharias \& Poldi, 2018). In this presentation, we focus on a case study analysis of social media posts associated with three of the 42 articles from The Conversation that contained COVID-19 preprint research. We selected these three articles because they received moderate to high levels of social media engagement and because they used preprints in qualitatively different ways. Using content analyses, we identified who is amplifying these media stories and how they are communicating about the (un)certain nature of this early COVID-19 research. 


\section{Acknowledgment}

Data from CrowdTangle, a public insights tool owned and operated by Facebook.

\section{References}

Corbett, J. B., \& Durfee, J. L. (2004). Testing Public (Un)Certainty of Science: Media Representations of Global Warming. Science Communication, 26(2), 129-151. https://doi.org/10.1177/1075547004270234

Deuze, M. (2008). The Changing Context of News Work: Liquid Journalism and Monitorial Citizenship. 18.

Deuze, M., Bruns, A., \& Neuberger, C. (2007). Preparing for an Age of Participatory News. Journalism Practice, 1(3), 322-338. https://doi.org/10.1080/17512780701504864

Dixon, G. N., \& Clarke, C. E. (2013). Heightening Uncertainty around Certain Science: Media Coverage, False Balance, and the Autism-Vaccine Controversy. Science Communication, 35(3), 358-382. https://doi.org/10.1177/1075547012458290

Fleerackers, A., Riedlinger, M., Moorhead, L., Ahmed, R., \& Alperin, J. P. (2021). Communicating Scientific Uncertainty in an Age of COVID-19: An Investigation into the Use of Preprints by Digital Media Outlets. Health Communication, 1-13. https://doi.org/10.1080/10410236.2020.1864892

Hermida, A. (2019). The Existential Predicament when Journalism Moves beyond Journalism. Journalism, 20(1), 177-180. https://doi.org/10.1177/1464884918807367

Karlsson, M., \& Strömbäck, J. (2010). Freezing the Flow of Online News: Exploring Approaches to the Study of the Liquidity of Online News. Journalism Studies, 11(1), 219. https://doi.org/10.1080/14616700903119784

Klawitter, E., \& Hargittai, E. (2018). Shortcuts to Well Being? Evaluating the Credibility of Online Health Information through Multiple Complementary Heuristics. Journal of Broadcasting \& Electronic Media, 62(2), 251-268. https://doi.org/10.1080/08838151.2018.1451863

Maggio, L. A., Krakow, M., \& Moorhead, L. L. (2020). 'There Were Some Clues': A Qualitative Study of Heuristics Used by Parents of Adolescents to Make Credibility Judgements of Online Health News Articles Citing Research. BMJ Open, 10(8), e039692. https://doi.org/10.1136/bmjopen-2020-039692

Majumder, M. S., \& Mandl, K. D. (2020). Early in the Epidemic: Impact of Preprints on Global Discourse about COVID-19 Transmissibility. The Lancet Global Health, 8(5), e627-e630. https://doi.org/10.1016/S2214-109X(20)30113-3

Metzger, M. J., Flanagin, A. J., \& Medders, R. B. (2010). Social and Heuristic Approaches to Credibility Evaluation Online. Journal of Communication, 60(3), 413439. https://doi.org/10.1111/j.1460-2466.2010.01488.x 
Newman, N., Fletcher, R., Schulz, A., Andi, S., \& Nielsen, R. K. (2020). Reuters Institute Digital News Report 2020 (p. 112). Reuters Institute for the Study of Journalism. https://www. digitalnewsreport.org/

Osman, K., \& Cunningham, S. (2020). 'Amplifier' Platforms and Impact. Australian Universities' Review, 62(1), 10.

Peters, H. P., \& Dunwoody, S. (2016). Scientific Uncertainty in Media Content:

Introduction to This Special Issue. Public Understanding of Science, 25(8), 893-908. https://doi.org/10.1177/0963662516670765

Zehr, S. (1999). Scientists' Representations of Uncertainty. In S. M. Friedman, S. Dunwoody, \& C. L. Rogers (Eds.), Communicating Uncertainty: Media Coverage of New and Controversial Science (pp. 59-79). Routledge. 


\title{
Paper 2
}

\section{THE CONVERSATION ON FACEBOOK: PATTERNS OF DISSEMINATION IN AUSTRALIA AND ANGLOPHONE CANADA}

\author{
Axel Bruns \\ Digital Media Research Centre, Queensland University of Technology \\ Michelle Riedlinger \\ Digital Media Research Centre, Queensland University of Technology \\ Jean Burgess \\ Digital Media Research Centre, Queensland University of Technology
}

\section{Introduction}

The Conversation's stated aim is "to provide access to quality explanatory journalism essential for healthy democracy" (The Conversation, 2021), but the provision of access alone is insufficient to this purpose: the content also needs to engage a broad and diverse public. The extent to which Conversation articles circulate beyond the website itself, and among which kinds of communities, is therefore an important set of questions. In addition to an assessment of on-site readership patterns for The Conversation's content, it is therefore also critical to investigate the extent to which Conversation articles circulate on leading social media platforms, and whether such circulation reaches a diverse audience or occurs predominantly amongst user communities that may already have a considerable affinity for scholarly perspectives.

This approach is especially critical since we know that a considerable component of the potential audience for news and information content no longer actively seeks out such materials, but encounters them more serendipitously via their social media networks (Newman et al., 2016: 99-101). If articles from The Conversation are to reach such larger and less active audiences, then, they will need to circulate widely on the major social media platforms in each country, and be shared by groups and individuals representing a broad range of interests and ideologies. Conversely, if they are posted only rarely, and receive only limited amplification via in-platform on-sharing (Wischnewski et al., 2021), or if such posting is limited to distinct communities of users (e.g. scholars and students), Conversation articles are likely to miss their mark.

\section{Approach and Method}

Therefore, this paper investigates the sharing patterns for content from The Conversation for its Australian and (Anglophone) Canadian editions - respectively the oldest and one of the youngest Conversation editions. We focus here especially on the circulation of Conversation content on Australian and Canadian Facebook pages, as Facebook remains the most prominent social media platform in both countries, and as 
available information on the geographic location of page administrators provides a useful proxy for identifying Australian and Canadian pages.

Further, we assess this circulation of Conversation articles in both countries alongside that of other mainstream news media content. Inspired by the work of Faris et al. (2017), and its adaptation and extension by Giglietto et al. (2018), who explored news engagement during the 2016 US and 2018 Italian elections, respectively, we use this broader sharing data to determine the relative affinity of Conversation content with the material published by other news organisations, and use background information about the specific audience demographics of those outlets to develop a perspective on the audiences that are likely to have encountered Conversation articles in their Facebook feeds.

For this research, we draw on the Facebook-owned data provider CrowdTangle as our data source. CrowdTangle offers data on the posting activities of public pages, public groups, and verified profiles on Facebook only; further, it classifies the country of origin of Facebook pages based on the geographic location of the majority of their administrators. While this introduces considerable limitations (our focus on public pages only means that we are unable to assess the sharing of Conversation URLs in public groups or in non-public Facebook spaces) and is likely to produce some false positives or false negatives (some pages may have outsourced their administration to teams located outside of Australia or Canada), in the absence of any other reliable access to Facebook data this approach nonetheless offers valuable insights.

Thus, for this analysis we have gathered all posts from public Facebook pages with a majority of administrators based in Australia and Canada, respectively, posted during the 2020 calendar year and containing a link to The Conversation or any of the top 40 Australian or top 70 Anglophone Canadian news domains (the smaller number of Australian news domains demonstrates the significant market concentration in Australia, which is dominated by a small number of major commercial news conglomerates). This resulted in datasets of 1,385,192 unique posts from Australian Facebook pages, containing 410,014 unique Australian news URLs (including 22,760 links to 9,048 unique Conversation URLs), and 1,262,318 unique posts from Canadian Facebook pages, containing 516,656 unique Canadian news URLs (including 3,412 links to 2,119 unique Conversation URLs).

\section{Preliminary Analysis and Further Outlook}

A work-in-progress visualisation of the Australian data at the domain level as a hybrid network containing both Facebook pages and the news domains they have linked to (fig. 1) already reveals some notable structural properties. Here, The Conversation has greater affinity with public broadcasters $A B C$ and $S B S$, and a cluster of broadly progressive outlets like The Guardian (which operates a distinct Australian edition), Crikey, or The New Daily, while it appears less close to a cluster comprised of the outlets of the conservative NewsCorp stable, including The Australian, Sky News Australia, and the Daily Telegraph, and the Australian edition of UK tabloid Daily Mail. 


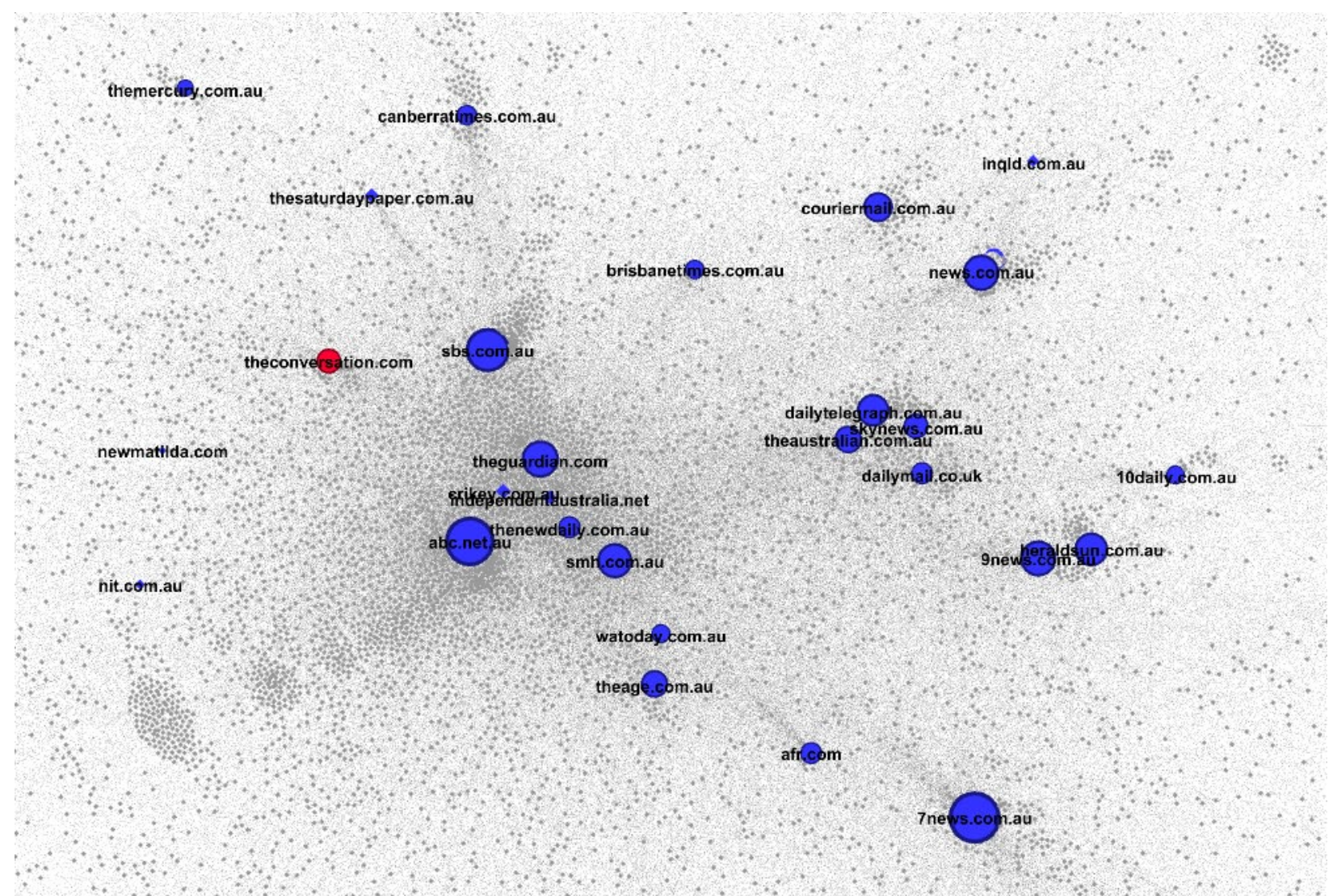

Fig. 1: bipartite network between Facebook pages (grey) and the Australian news domains they link to (blue; Conversation highlighted in red)

In further analysis, we plan to convert this bipartite network to two monopartite networks (between domains and between pages only, respectively), in order to better assess the relative affinity between the domains being shared, and between the pages sharing them. This will also take into account available information about how these pages define themselves, through their descriptions and categorisation. We will also conduct in-depth manual and computational coding and analysis to identify the most prominent themes of the Conversation articles being shared in each country, and in the countryspecific network clusters that emerge from our network analysis, as well as of the Facebook post texts accompanying these shared links, and examine the patterns of engagement with these posts on Facebook.

A first exploration of the Australian data has already revealed that of the ten most frequently posted Conversation URLs in Australian pages, eight address issues relating to climate change and the environment, one addresses Australia's history with slavery, and only one centrally focusses on the pandemic. While devastating bushfires were a major story in Australia in the first months of 2020, this is somewhat surprising given the overwhelming attention paid to COVID-19 in the remainder of the year, and the role scientific work plays in understanding and addressing it. However, it is possible that insights relating to coronavirus are spread across a larger number of Conversation articles which in aggregate reached a large Facebook audience even if none were shared especially widely, and that our further analysis will identify these in the data. In Anglophone Canada, meanwhile, the two top articles cover the COVID-19 crisis, while 
others in the top ten predominantly address issues related to Indigenous discrimination and gender equality.

From our further mixed-methods analysis, we expect additional distinct patterns to emerge. These should indicate, for both country editions of The Conversation, whether and to what extent they have managed to address a broad and diverse audience of Facebook communities, and whether there remain specific demographically or ideologically defined communities who have yet to engage with The Conversation and its efforts to communicate scientific research to a wider audience. We anticipate that the Australian edition of The Conversation will have made greater inroads towards its goals over the ten years of its existence, but also that the different social, media, and political environment in Canada will have directly affected the emerging positioning of the Canadian edition in its domestic media landscape.

\section{Acknowledgment}

Data from CrowdTangle, a public insights tool owned and operated by Facebook.

\section{References}

The Conversation. (2021). Who We Are. https://theconversation.com/au/who-we-are

Faris, R., Roberts, H., Etling, B., Bourassa, N., Zuckerman, E., \& Benkler, Y. (2017). Partisanship, Propaganda, and Disinformation: Online Media and the 2016 U.S. Presidential Election (Berkman Klein Center Research Publication No. 2017-6). Social Science Research Network. https://papers.ssrn.com/abstract=3019414

Giglietto, F., lanelli, L., Rossi, L., Valeriani, A., Righetti, N., Carabini, F., Marino, G., Usai, S., \& Zurovac, E. (2018). Elezioni-2018: Mapping Italian News. LaRiCA at Università di Urbino Carlo Bo. https://elezioni2018.news/blog/report/23

Newman, N., Fletcher, R., Levy, D. A. L., \& Nielsen, R. K. (2016). Reuters Institute Digital News Report 2016. Reuters Institute for the Study of Journalism, University of Oxford. http://reutersinstitute.politics.ox.ac.uk/sites/default/files/Digital-News-Report2016.pdf

Wischnewski, M., Keller, T., \& Bruns, A. (2021). Shareworthiness and Motivated Reasoning in Hyper-Partisan News Sharing Behavior on Twitter. Digital Journalism. https://doi.org/10.1080/21670811.2021.1903960 


\title{
Paper 3
}

\section{NOVEL INTERFACES IN SCIENCE COMMUNICATION: COMPARING JOURNALISTIC AND SOCIAL MEDIA UPTAKE OF ARTICLES PUBLISHED BY THE CONVERSATION AFRICA}

\author{
Lars Guenther \\ Department of Social Sciences, University of Hamburg \\ Marina Joubert \\ CREST, Stellenbosch University
}

\section{Problem Statement: The Nature and Impact of The Conversation Africa}

Science amplifier platforms such as The Conversation (Osman \& Cunningham, 2020) have recently gained popularity in a changing media ecosystem in which the traditional roles of journalists are eroded (e.g., Brossard, 2013; Guenther, 2019), and scientists are urged to engage with society (e.g., Agaba, 2019). The Conversation constitutes a blend of scientific communication, science communication, and science journalism, and a convergence of the professional worlds of science and journalism. Thus, it challenges the traditional roles and norms of scientists and journalists in the news production process (e.g., Nelkin, 1995). At the same time, there might be improvement regarding science-media interactions that have traditionally been described as tense and characterized by mistrust (e.g., Dunwoody et al., 2009). Because scientists have the final say about the content, they become stronger agenda setters (e.g., McCombs \& Shaw, 1972). Since research so far has paid little attention to science amplifier platforms, their agenda setting function, let alone The Conversation's Africa edition, our focus is directed to the nature of The Conversation Africa (henceforth: TC Africa). Thus, we aim to characterize TC Africa as a science amplifier platform in terms of its publication trends, authors, and content.

In addition, The Conversation is not just an agenda setter. By making its content freely available for republishing and sharing, it has become an inter-media agenda setter for journalistic and social media, and thus aims to increase its impact on wider audiences. Journalists and social media users, nevertheless, are different audiences. For journalistic media, a large number of studies focusses on how science journalists select news, as well as which professional routines, norms, and values they apply (e.g., Fahy \& Nisbet, 2011; Nelkin, 1995). Science journalists have been found to rely heavily on scientists as experts (e.g., Amend \& Secko, 2012; Dunwoody, 1999), which makes it likely that they may use content from The Conversation. However, their professional selection criteria still apply, and this could affect what kind of articles they select.

At the same time, although scientific topics peak similarly in journalistic media and social media, there are differences in sources, topics, and tone (e.g., Veltri \& Atanasova, 2017), which may also lead to different agendas. Furthermore, social media provide indicators of how audiences deal with content, for instance through social media 
shares (e.g., Brossard, 2013). Research to date has only started to analyze what triggers social media engagement with science (e.g., Hargittai et al., 2018), with studies showing that engagement is more likely when information has a negative or emotional tone and when it is relevant for a large number of people (e.g., Veltri and Atanasova, 2017). Consequently, we also aimed to determine how TC Africa acts as an inter-media agenda setter, and to assess whether this varies between journalism (through republishing of articles) and social media (through social media engagement, e.g., the number of shares).

\section{Methods and Findings}

We obtained data from the Johannesburg head office on all articles published over a five-year period since the launch of TC Africa, i.e., from 7 May 2015 to 6 May 2020 ( $N=$ 5,392 ). The data set included the publication dates, titles, keywords, authors (with affiliations and countries), thematic sections, as well as the number of times each article was republished in the mainstream media or shared on Facebook and Twitter.

We incorporated the data into SPSS and VOSviewer (Van Eck and Waltman, 2020) for analysis. The latter was used for topical clustering of keywords. After unifying the 7,640 different keywords for all articles in the sample, the algorithm identified the 782 keywords that occurred a minimum of 10 times. We used the top $60 \%$ of them (469 keywords), identified eight topical clusters, and created visual networks for data interpretation. We then included republishers, Facebook, and Twitter shares as score values.

The findings for our first research aim (i.e., the nature of TC Africa) showed that the number of articles remained steady over the course of five years, with an average of 89 articles per month. Most of the articles were written by a single author $(N=4,390 ; 81 \%)$ and most authors $(N=3,897 ; 56 \%)$ were from South Africa. From the seven thematic sections of TC Africa, most articles were published in the Politics + Society section ( $\mathrm{N}=$ $1,524 ; 29 \%)$, followed by Business + Economy $(\mathrm{N}=788 ; 15 \%)$, Health + Medicine $(\mathrm{N}=$ $773 ; 15 \%)$, and Environment + Energy $(\mathrm{N}=719 ; 14 \%)$. The analysis of the eight topical clusters showed that most articles fall into the category Academia, Research, History, and Education, with Wildlife, Conservation, and Climate Change and Health and Disease in second and third places.

For our second research aim (i.e., the impact of TC Africa), we found that republishing and Facebook shares increased over the five years, but Twitter shares decreased. Regarding differences in journalistic and social media uptake, we observed that journalistic republishing was most frequent for articles published in the Business + Economy and Politics + Society sections, while among social media users, sharing was more frequent for articles from the sections Education, Environment + Energy, and Science + Technology. This was supported by the topical clusters: Journalistic media favored all political topics; in contrast, on Facebook and Twitter, topics related to social issues were shared more frequently.

We aim to discuss these findings on (inter-media) agenda setting of a science amplifier platform with audience members after the presentation. 


\section{References}

Agaba J (2019) New AAS Funding Model Calls for Greater Public Engagement, University World News. 19 June. Available at:

https://www.universityworldnews.com/post.php?story=20190625170710329 (Accessed 22 March 2021).

Amend E and Secko DM (2012) In the Face of Critique: A Metasynthesis of the Experiences of Journalists Covering Health and Science. Science Communication 34(2): 241-282.

Brossard D (2013). New Media Landscapes and the Science Information Consumer. Proceedings of the National Academy of Sciences 110 (3): 14096-140101.

Dunwoody S, Brossard D and Dudo A (2009) Socialization or Rewards? Predicting US Scientist-Media Interactions. Journalism \& Mass Communication Quarterly 86(2): 299314.

Fahy D and Nisbet MC (2011) The Science Journalist Online: Shifting Roles and Emerging Practices. Journalism 12(7): 778-793.

Guenther L (2019) Science Journalism. In: Ornebring H (ed.), Oxford Encyclopedia of Journalism. New York: Oxford University Press.

Hargittai E, Füchslin T and Schäfer MS (2018) How Do Young Adults Engage with Science and Research on Social Media? Some Preliminary Findings and an Agenda for Future Research. Social Media \& Society 4 (3): 1-10.

McCombs ME and Shaw D (1972) The Agenda-Setting Function of the Mass Media. Public Opinion Quarterly 69: 813-824.

Nelkin D (1995) Selling Science: How the Press Covers Science and Technology. New York: Freeman.

Osman K and Cunningham S (2020) 'Amplifier' Platforms and Impact: Australian Scholars' Use of The Conversation. Australian Universities Review 62(1): 41-50.

Van Eck NJ and Waltman L (2020) VOSviewer Manual. Available at: vosviewer.com/documentation/Manual_VOSviewer_1.6.15.pdf (accessed 15 March 2021).

Veltri GA and Atanasova D (2017) Climate Change on Twitter: Content, Media Ecology and Information Sharing Behaviour. Public Understanding of Science 26 (6): 721-737. 


\section{Paper 4}

\section{INCREASING ACCESS TO RESEARCH VIA AMPLIFIER PLATFORMS: EXPLORING PUBLIC ENGAGEMENT WITH THE CONVERSATION ARTICLES}

Kim Osman

Queensland University of Technology

Axel Bruns

Queensland University of Technology

Jean Burgess

Queensland University of Technology

\section{Extending the Reach of Academic Research via Amplifier Platforms}

Using digital media logics of sharing, republishing and reusing, amplifier platforms like The Conversation (Osman \& Cunningham, 2019) are uniquely placed to increase access to academic research. These platforms enable flows of information across academic, news and social media sites and facilitate scholars to reach many different publics (Papacharissi, 2015). Prior to 2020, these platforms were relatively niche sites of emerging non-profit journalism; however, in March 2020, visits to The Conversation in Australia and New Zealand doubled from the previous month to more than 26 million reads, while according to Nielsen figures for the same period the Australian Broadcasting Corporation had 15.2 million and The Guardian a record of 11.6 million reads (Ketchell, 2020). The Conversation has therefore established itself as a key media organisation and platform in Australia, with a significant audience reach globally.

The proposed paper sits at the nexus of two increasingly important issues for society and scholars - the need for both accurate and accessible information in a crowded media sphere; and the need to prove the impact of publicly-funded research in a competitive academic funding environment. Through an analysis of high-performing articles from The Conversation and interviews with its academic authors we seek to develop new ways of measuring the extent, depth, and diversity of public conversation generated around the scholarly contributions published on amplifier platforms.

\section{Understanding the Impact of Academic Research via Engagement Metrics}

The proposed paper extends the research of Hargittai et al. (2018) and Terras (2012) on public engagement with science on social media. Specifically, our study identifies the types of articles that have the most engagement on two distinct digital media platforms, The Conversation's own website and Facebook, that are used by academics for communicating research and information, and reviews scholars' experiences of public engagement on social media and amplifier platforms. 
Public engagement (via talks to community groups, membership of committees, etc.) is a reporting requirement for many academics in evaluating their scholarly impact and job performance (Johnstone, 2017). This paper discusses how The Conversation authors frame and use social media metrics in reporting their research translation and public engagement activities to their universities, employers, and funders. Discussion about academic research across social media platforms is varied, and levels of reach and impact are not always reflected by the number of likes and shares a post receives. We therefore use interview data to capture individual examples of the engagement that can happen away from theconversation.com and on different social media.

It was so fascinating...it didn't get a lot of hits, but there was someone in the Canadian government who reposted it on Linkedln... when he reposts it, it goes out and his contacts are not in my field. It's fascinating to watch...You're always in your own world, right? But then we are only speaking to our own people all the time. He really taught me the importance of reaching different areas. We've had really interesting conversations since then, and watching things get reposted on Linkedln, it's become quite an experiment for me.

It's interesting, that feedback that you get on social media. She wasn't saying it to me. It was to whatever following she had in the UK. But it meant a lot to me because she's a professional and works with [stakeholders]. It meant something. That was important to me.

Understanding how amplifier platforms like The Conversation integrate with social media in a complex digital media ecosystem where academic and scientific information sits alongside news, personal updates, and entertainment (Burgess et al., 2019) is important. Increased social media engagement potentially leads to increased reach, and a significant amount of interaction and engagement with academic work happens on social media. This study is further a step towards identifying the different audiences for The Conversation, and for academic research across platforms more broadly, and towards assessing what "public engagement" looks like on different digital and social media.

\section{Methods}

The Conversation provided us with access to its internal metrics, enabling us to identify its most popular articles (as determined by page visits), and those with the most engagement (using the number of on-site comments as a proxy of public engagement). We further used the social media monitoring tool CrowdTangle to identify URLs from theconversation.com that were shared by public groups, public pages, and verified profiles on Facebook. Combining the metrics from both platforms over a nearly ten-year period, from The Conversation's launch in March 2011 to 1 December 2020, in this paper we compare the characteristics of high-performing articles and the levels of public engagement with academic content across The Conversation and Facebook. 
In addition to this quantitative work, we also interviewed high-performing authors from both the Australian and Canadian editions of The Conversation about their experiences of publishing on amplifier platforms and public engagement on social media.

\section{Public Engagement with The Conversation Articles on Social Media}

86,467 articles from The Conversation were shared publicly on Facebook between March 2011 and December 2020, in 416,391 individual Facebook posts. But the comparison between external CrowdTangle and internal Conversation data reveals that such social media engagement does not necessarily translate into increased readership of the articles themselves. We use the article categories developed by the scholars who authored the articles, and the Conversation editors who supported their development, to examine the levels of engagement with different topics across both platforms. We also identify which articles generate what types of engagement as indicated by Facebook reactions - what articles prompt a "sad" response, or an "angry" response? This analysis is complemented by interview data from The Conversation authors who covered a variety of such topics in their article contributions.

Building on these reflections from authors, the paper concludes by exploring the ways in which scholars themselves may leverage social media engagement with their work to demonstrate impact and increase the public value of their research.

\section{Acknowledgment}

Data from CrowdTangle, a public insights tool owned and operated by Facebook.

\section{References}

Burgess, J., Bruns, A., \& Osman, K. (2019). Analysing Scholarly Contributions to Public Debate with Social Media Issue Mapping: A Case Study of the Australia Day Controversy. Communication Research and Practice, 5(4), 393-407. https://doi.org/10.1080/22041451.2019.1689688

Hargittai, E., Füchslin, T., \& Schäfer, M.S. (2018). How Do Young Adults Engage with Science and Research on Social Media? Some Preliminary Findings and an Agenda for Future Research. Social Media + Society. https://doi.org/10.1177/2056305118797720

Johnstone, A., \& Moffat, I. (2017, May 25). Opinion: Time to Embrace Public Engagement to Secure Research Funding. Campus Review. https://www.campusreview.com.au/2017/05/time-to-embrace-public-engagement-tosecure-research-funding/

Ketchell, M. (2020, April 15). There's a Good Chance You're New to The Conversation - Here's How We Deliver News Differently. The Conversation. https://theconversation.com/theres-a-good-chance-youre-new-to-the-conversationheres-how-we-deliver-news-differently-136400 
Osman, K., \& Cunningham, S.D. (2019). Engagement and Impact through 'Amplifier Platforms'. Australian Universities' Review, 61(2), 42-48.

Papacharissi, Z. (2014). Affective Publics: Sentiment, Technology, and Politics. Oxford University Press. https://doi.org/10.1093/acprof:oso/9780199999736.001.0001

Terras, M. (2012). The Impact of Social Media on the Dissemination of Research:

Results of an Experiment. Journal of Digital Humanities, 1(3).

http://journalofdigitalhumanities.org/1-3/the-impact-of-social-media-on-thedisseminationof-research-by-melissa-terras/ 